\title{
Cultural Strategy in Primary School English Teaching in Linzhi District
}

\author{
Xu Jie \\ School of Teacher Education, Lingnan Normal University, Zhanjiang, China \\ Email address: \\ 63903429@qq.com \\ To cite this article: \\ Xu Jie. Cultural Strategy in Primary School English Teaching in Linzhi District. International Journal of Elementary Education. \\ Vol. 8, No. 2, 2019, pp. 45-52. doi: 10.11648/j.ijeedu.20190802.12
}

Received: April 12, 2019; Accepted: May 23, 2019; Published: June 13, 2019

\begin{abstract}
English curriculum in primary school is offered in Grade three Chinese compulsory education system, even it has been set up in Grade one in economically developed regions. Learning a language does not mean that to learn its vocabulary and grammar is sufficient enough to use the language correctly and have successful cross-cultural communication. The rich connotation, as the remarkable feature of language, it is beneficial to cultivate the pupil's cultural awareness of English countries for correctly understanding and using English properly while cross-cultural communications occurring, for deepening the pupil's understanding of traditional great culture of Chinese people, for fostering consciousness of patriotism. The results of questionnaire survey which researched by 150 pupils in Gongbujiangda County, Linzhi District, Tibet, showed the pupil's cultural awareness for English countries directly. Pupils have known something for elemental culture of these countries, but it is not enough, and the weakness for cultural awareness results to their weakness for comprehensive language application ability generally, and the failure that easily shows its place in the communication. According to the above research, three suggestions are put forward to solve these problems. The first one is that primary school English teachers need to increase personal English culture quality. Make use of textbooks to compare cultural difference with cultural infiltration as the second one. And the other one is various channels for cultivating cultural awareness by multimedia.
\end{abstract}

Keywords: Primary School English, Cultural Awareness, Strategy, Linzhi District

\section{Introduction}

\subsection{Significance of the Research}

Cultural awareness is not only able to enhance students' comprehensive ability of language use but also expand their horizon, and strengthen patriotism awareness. After all, the world has colorful culture while China shares the reputation as the unique one. The effective cultural strategy in primary school is beneficial for students to learn English, correctly understand and appropriately use it, especially in trilingual area Linzhi District, where Tibetan is used as first language, Chinese is the second language and English is learned as the third language. Students are able to know Chinese aged and now outstanding culture better, and do not detract ourselves but not overrate others. Keeping cultural equality and patriotism feelings in their mind in the young age is helpful for them to promote cultural consciousness.

Since the promulgation of English Curriculum Standards for Senior High School in 2017, the core competency of English subject has attracted much attention, especially the cultural awareness, which has attracted more and more scholars to carry out relevant researches. However, most of the research objects are middle school students, and there are few studies on the cultural strategies of primary school students. Little is known about Tibetan primary schools. With the deepening of the new round of basic education curriculum reform and the implementation and promotion of new curriculum standards, the original teaching philosophy and teaching mode in Tibetan primary schools are not compatible with the rapid development of the economy and society, especially there is a big gap between Tibet and other provinces and regions in China, which restricts the cultivation of English talents to a large extent. 


\subsection{Aims of the Research}

This study aims to summarize the previous study of cultivating English cultural awareness in primary schools between China and other countries, and explore how to enhance students' comprehensive ability of language use while learning language knowledge and educating the national confidence, patriotism and international perspective. At the same time, the questionnaire is inquiry for the pupil's English cultural awareness, then the reasons why primary school students have soft spots in English cultural awareness that is potential to bring about failure in cross-cultural communication will be analyzed. In the end, there are some ways for fostering English cultural awareness.

This paper studies the English teaching in primary schools in Tibet, finds out the existing problems in cultural strategy of the English teaching in Tibet, and puts forward corresponding suggestions and countermeasures for the existing problems in Linzhi District. This will not only help to raise the awareness of the importance and urgency of cultural strategy in English teaching in Tibetan primary schools, but also push the competent education departments at all levels to take effective measures to strengthen the guidance and management of primary school English teaching in Tibet.

\section{Literature Review}

The definition of culture will be introduced in this chapter, including process of primary school English and a brief account of the relevant studies of cultural awareness cultivation in primary school.

\subsection{The Definition of Culture}

Different people have different viewpoints for what culture mean from different perspectives. Anthropologist Edward Taylor says about culture or civilization, as for its comprehensive ethnological meaning, is complex whole that including knowledge, belief, art, morality, legislation, custom, and everybody who as members of society acquire abilities and habits in 1871. [1] This theory had unshakable position for cultural definition in Taylor's time, and it became the cornerstone for other theories about cultural definition which developed later. Li Jianhua thinks that culture is defined as a framework in our lives, something that affects our values, attitudes and behavior. [2] Language is integral part from culture, and culture restricts the expression of language for the world. In the same time, language is spoken by people to show their native culture, which mirror the way of thinking and definition of emotion, including value. It can be found in SWH (Sapir-Whorf hypothesis). Culture, in a broad sense, means integrated pattern of human knowledge, belief, and behavior that are both a result of an integral to the human capacity for leaning and transmitting knowledge to succeeding generations. [3] Culture should be updated with development of society which lead to thought concept transformation, and culture and society can affect each other and then promote progress for both themselves. Society will not step forward without cultural renewal, and human being will stay with prehistoric barbarism if society without development, just like animals, not to mention that people have capabilities to find better version of selves and build a better world for human being. Zhang Yueying presents that in fact, it is almost impossible to definite the culture because of the complexity of the cultural connotation [4]. So, at present the definitions for culture mainly aim at one aspect, mentally or materially.

\subsection{Primary School English Teaching in China}

In the late Qing Dynasty and the early Republic of China, the special period of Chinese social revolution, primary school English had been brought in some ecclesiastical schools which ran courses such as reading the Bible by clerics. But in this time, English was propagated in small range within achieved different accomplishment for students, which could not be official and systemic education, although it did strike Chinese traditional education. From the society changes with the development of age, Russian as primary foreign language course resulted in huge shock for English. After the Great Cultural Revolution, anything in China was waiting for reestablishment, especially in field of foreign language education. With the college entrance examination restarted, English was beginning to fix itself underneath the government's support. But during this period, primary school English teaching had many problems because of out of scientific guidelines, and due to the unbalanced economic development, its popularization wasn't balanced seriously. Backward textbook and teaching philosophy, jagged quality of teachers are part of the reasons. However with the process of global economic integration boosting, an increasingly number of diplomacy and culture communications, primary school English education is valued by various countries which native language isn't English. China naturally will not make retrogression. Comply with the development of times and to meet the growing needs of people for humanistic quality, English curriculum was offered increasingly from third grade of primary school since the autumn in 2001, as integral part for TEFL. According the study, over $71 \%$ the town's primary school has already offered English course in 2006, more than $31 \%$ in the countryside. Hence primary school English education has become regularly and systematically, with relevant teaching theories and studies developing, investment of scholastic English teaching increasing, the shift of perspective of people, still the guidelines from government, primary school English education will have a promising future.

As for the English teaching in Linzhi District, Primary schools students learn English as a course from Grade 3 according to the national curriculum plan. Kindergarteners only begin to learn to speak Chinese when they get the opportunity to receive the preschool education. Chinese learning which offers the possibility to learn about different culture and tradition, has great impact for the learners in Linzhi, a Tibetan-speaking area, Nowadays, pupils in 
Gongbujiangda County are available to learn English in the village schools which are far-away form the county.

\subsection{The Relevant Studies of Cultivation for Cultural Awareness}

More than tens of thousands of Chinese documents can be searched in CNKI while make "primary school English cultural awareness" as key words for seeking, and similar quantitative foreign literature show themselves by searching "primary English" and "language and teaching". Foreign relevant studies are earlier than domestic.

J. Liaghatdar, N. Yamani, F. Mohseni consider that since, globalization is not avoidable but a process which takes the whole world and on the other hand, and English language is considered the international language though which many economical, scientific, political, and cultural communications take place, and we need to reconsider the policies concerning learning English as a foreign language specially to start it in primary school. [5] It needs to base on domestic situation for government to make educational outline, from economy, politics and local culture. China has updated curriculum standards for English teaching named The Compulsory Education English Curriculum Standards in 2011, including the functions of English, principles for how to teach and learn it, five inseparable parts for students' comprehensive ability of language use, goals for learning in different stages, and the qualities of textbook, etc. These details are all formulated by Ministry of Education to guide teachers and students to teach and learn English scientifically within direction that at the service of cultivating comprehensive talents for China. 'In 80s of 20 century, Bryam (1989) in his masterpiece Cultural Studies in Foreign Language education (1989) considered foreign language education needed to cover language study, cultural experience, language comprehension and cultural comprehension.' [6] 'Lado regards as that it is impossible to learn language indeed without pattern and criterion of culture.'[7] American ESL curriculum standard points eight perspectives for language, including the process of language isn't developing independently, and there is coexistence between language and culture study. Li Yun, Wang Qun and Xing Yaoyao mention cultural factors are inflected many linguistic phenomena such as syntactic structure and lexical meaning. The huge cultural differences between China and western countries make different ways for people's thinking [8]. There are various explanation for the same word in two cultures. For example, white. In Chinese, the white is a taboo means sadness and death usually, so it symbolizes misfortune. However, the word in western culture on behalf of pure and holy, it means integrity and honest. For example, the bride will dress in white for her wedding, phrases a white spirit, white hand, white market in English. Pragmatic errors will occur if communicators don't know cultural background with each other.

Li Jianhua considers when learning English, students are not only expected to learn its pronunciation, grammar, words and idioms but also expected to learn English-speaking countries' cultures, such as their ideas, customs, and behavior of the society [9]. This shows that language and culture can't be separated while learning English. The value is the most important part of culture. It is good to cultivate cultural sensitivity for developing logical ability of thinking of students, and then for promoting advance of their comprehensive quality. 'Primary school is the important stage for groundwork, so it is necessary to learn authentic English for students in the beginning, and teachers need to put infiltrate of cultural awareness into the prominent position.' [10] 'Primary school English culture teaching is beneficial for cultivation of pupil's interest for learning English, strengthening their motivation for English learning, improving cross-cultural communicative ability for them' [11]. Then Tan Li mentions for those learners who doesn't live in target language culture, it is particularly important to learn foreign culture consciously for them, in which can replenish, arrange and deepen cultural information that acquired by acquisition for more effective acquisitions of culture [12]. Chinese government offers primary school English in the third grade, and pupils whose age in this stage is helpful to learn it. In this period, pupils' solidification of mother tongue Chinese isn't evident and the influence is much weaker, comparing with they grow up. And pupils have more interesting for something new that urge them to explore the unknown field, also stronger thirst of knowledge accept things they doesn't know before. According to the psychological features of pupils, permeating cross-cultural awareness is able to help students to recognize goal of learning foreign language and keep their learning interests, at the same time, for training ability of logical thinking. Guan Jing points cultural awareness always as the invisible course for English, therefore teachers is easy to ignore its cultivation. [13] Guang Lilan mentions although there are so many theories for teaching foreign language culture, and the importance of cultural teaching is gradually accepted by people, it need to deeply explore and study not only for how to combine cultural teaching and English teaching effectively in primary stage but also for what way to introduce theory into realistic classroom instruction, and others problem. [14]

In CNKI, the searching results reflect relevant literature about English cultural awareness cultivation and cross-cultural communication ability is mostly for students from college and high school, and literature for primary school English teaching is obviously less than former one. It is embodying culture teaching for primary school English doesn't be paid enough attention to as basic of cultivating comprehensive language use ability.

\section{The Questionnaire and Analysis for English Cultural Awareness of Primary School Students}

\subsection{Research Background}

Gongbujiangda County belongs to Linzhi District of Tibet 
autonomous region. It is located in the southeast of Tibet autonomous region and the northwest of Linzhi city. The county covers a total area of 11,650 square kilometers and has jurisdiction over 3 towns and 6 townships, with a permanent population of about 40,000. The average elevation is 3600 meters. There are 8 primary schools in Gongbujiangda County, which includes 7 rural schools, where the number of students ranges from 200 to 500. Only one is in the county, which is called Gongbujiangda County Primary School, whose number of students is about 1000 . Cuogao primary school and Niangpuxiang primary school are located at the altitude of over 4,600 meters. Whether rural or county schools, school teaching conditions are not much different, there are multimedia platforms. Internet is available in every classroom. The number of students in every primary school is about $30-40$ per class. The textbook used by the students is New PEP.

\subsection{Investigative Objectives and Purposes}

All the primary schools are adhering to the education idea that people oriented and lay the foundation of lifelong learning for students. And the special school mottoes and management of strategies take shape distant school-running characteristics, morality education practice study as light spot, English and art education have become outstanding features. A compact study needs logical theory, a lot of real and effective data. Therefore this chapter obtains the most original information from pupils from fifth grade at mentioned above schools, in order to seek real condition of cultural learning, pupils' grasp level for English cultural awareness and knowledge.

\subsection{Questionnaire Design}

The questionnaires are delivered 150 parts totally and recycled 150 parts, $100 \%$ recovery. Passing serious check to every questionnaire, everyone is effective, $100 \%$ efficient. In the view of the New PEP (2012) for primary school, this questionnaire includes 15 questions for English knowledge culture and communicative culture, involving architecture, custom, geography, social etiquette and so on.

\subsection{The Result and Analysis of Questionnaire}

After recovery of questionnaires, author makes statistic for every questions on it. At the same time, detailed analysis will be processed for results.

Table 1. The Results of English Knowledge Culture.

\begin{tabular}{lllll}
\hline & Title number & Options & Number & Percentage \\
\hline & & $\mathrm{A}$ & 81 & $54 \%$ \\
& 1 & $\mathrm{~B}$ & 50 & $33 \%$ \\
& & $\mathrm{C}$ & 13 & $8 \%$ \\
Knowledge & $\mathrm{D}$ & 8 & $5 \%$ \\
Culture & & $\mathrm{A}$ & 12 & $11 \%$ \\
& 2 & $\mathrm{~B}$ & 23 & $15 \%$ \\
& & $\mathrm{C}$ & 105 & $70 \%$ \\
& 3 & $\mathrm{D}$ & 6 & $5 \%$ \\
& 3 & $\mathrm{~A}$ & 14 & $9 \%$ \\
\hline
\end{tabular}

\begin{tabular}{|c|c|c|c|}
\hline Title number & Options & Number & Percentage \\
\hline \multirow{6}{*}{4} & B & 23 & $15 \%$ \\
\hline & $\mathrm{C}$ & 107 & $70.2 \%$ \\
\hline & $\mathrm{D}$ & 6 & $4 \%$ \\
\hline & A & 129 & $86 \%$ \\
\hline & B & 17 & $11 \%$ \\
\hline & $\mathrm{C}$ & 4 & $3 \%$ \\
\hline \multirow{4}{*}{5} & A & 33 & $21 \%$ \\
\hline & B & 4 & $3 \%$ \\
\hline & $\mathrm{C}$ & 107 & $70.2 \%$ \\
\hline & $\mathrm{D}$ & 6 & $4 \%$ \\
\hline \multirow{4}{*}{6} & A & 105 & $70 \%$ \\
\hline & B & 26 & $17 \%$ \\
\hline & $\mathrm{C}$ & 13 & $9 \%$ \\
\hline & D & 6 & $4 \%$ \\
\hline \multirow{4}{*}{7} & A & 33 & $22 \%$ \\
\hline & B & 38 & $25 \%$ \\
\hline & $\mathrm{C}$ & 41 & $28 \%$ \\
\hline & $\mathrm{D}$ & 38 & $25 \%$ \\
\hline \multirow{3}{*}{8} & A & 99 & $66 \%$ \\
\hline & B & 39 & $26 \%$ \\
\hline & $\mathrm{C}$ & 12 & $85 \%$ \\
\hline \multirow{3}{*}{9} & A & 117 & $78 \%$ \\
\hline & B & 28 & $19 \%$ \\
\hline & $\mathrm{C}$ & 5 & $3 \%$ \\
\hline \multirow{3}{*}{10} & A & 6 & $4 \%$ \\
\hline & B & 140 & $93 \%$ \\
\hline & $\mathrm{C}$ & 4 & $3 \%$ \\
\hline
\end{tabular}

The first part is aimed at students' level for knowledge culture. The data reflects that the pupils' situation isn't ideal as expected. It is just only $54 \%$ of students to choose the right option, A, for the first one. And as much as $33 \%$ of students choose option B, Mary. This situation mirrors it's very serious culture negative transfer in English learning for the students. In English culture, the first name is given name and last name as family name, which is totally opposite in Chinese. For the second one, although $70 \%$ students choose the right one, $\mathrm{C}$, there are $30 \%$ of the students choose the wrong ones. They have learned something about Christmas in Unite 2 What's your favourite season from New PEP, Book 6. And Christmas is so popular in China, no matter what TV, internet or shopping mall, the advertisements and slogans are anywhere. It is other mistake shouldn't occur. The third for icon, $70.2 \%$ accuracy, maybe it is relative to children's psychology and animal enjoyment. The fourth is about country's capital, $86 \%$ choose the right one, but comparatively major students choose B, France, perhaps there are many of them can't figure out Britain and France because Chinese often say two countries together as 'ying fa', other example for culture negative transfer. The fifth is also higher error score relatively, major students choose New York as capital of America, maybe because they have heard the word New York frequently therefore equate the biggest city New York of America with its capital, after all, the biggest one Beijing is Chinese capital. The sixth for landmark building in Britain, $70 \%$ of then chose the right answer, but still 6 students show they don't know which one to choose, maybe they never know of it before. The seventh is certain difficult, which is about taboo in Christian culture, and students need to know definite western culture for this one, from the data, the accuracy and error rate are close. But 
there are $28 \%$ of students made it. The eighth for royalty, representative figure of English culture, and only $66 \%$ of students are correct, the others show their mistakes or they don't know this. Maybe major of them need to watch news to learn something new that doesn't be showed in the textbook of the stage. The ninth is the typical one to check how many students are suffering negative transfer from Chinese traditional culture, it is normal to live with parents for Chinese adult, even if times change, many of students in Linzhi District still live with their grandparents. When it comes to Chinese tradition, $78 \%$ of them choose 'No' and $19 \%$ of then choose 'Yes', 3\% show they don't know. Next one 93\% of the students choose the right answer, although 3\% show they don't know it. But answer situation is the optimal for question 10 .

Table 2. The Results of English Communicative Culture.

\begin{tabular}{lllll}
\hline & Title number & Option & Number & Percentage \\
\hline & & A & 9 & $6 \%$ \\
& \multirow{2}{*}{11} & B & 17 & $11 \%$ \\
& & C & 120 & $80 \%$ \\
& \multirow{2}{*}{12} & D & 4 & $3 \%$ \\
& A & 96 & $64 \%$ \\
Communicative & \multirow{2}{*}{13} & B & 48 & $32 \%$ \\
Culture & & C & 6 & $4 \%$ \\
& & A & 28 & $18 \%$ \\
& & B & 51 & $34 \%$ \\
& & C & 71 & $48 \%$ \\
& & D & 0 & 0 \\
& & A & 15 & $10 \%$ \\
& & B & 13 & $9 \%$ \\
& & C & 122 & $81 \%$ \\
& & D & 0 & 0 \\
& & A & 120 & $80 \%$ \\
& 15 & B & 17 & $11 \%$ \\
& & C & 11 & $8 \%$ \\
& & D & 2 & $1 \%$ \\
\hline
\end{tabular}

Question 11 checks students' knowing for American dream, in which accuracy is more than error score, so it is ideal for this part. But students are under expectation in question 12 , and more than $64 \%$ of the students don't do it correctly while they accepting gifts from foreign friends, and they do it in Chinese style. It is an improper act in cross-cultural communication with someone from English country. Question 13 checks the taboo of communication; only $28 \%$ of the students know it is improper to ask others' age in communication. Question 14 checks how to greet, but still $19 \%$ of the students take Chinese way to greet foreign people. And the last one checks how to reply compliment in English, and still some students respond with Chinese way, but $81 \%$ of them know how to say is suitable, so question 14 and 15 are both ideal for answer situation.

From what data show above, students know certainly English culture, but their cultural awareness is weak, as low grasp level because of mainly Chinese culture negative transfer. The core of culture is value. However, students still use representative Chinese thinking way to think and act in cross-cultural communication, the reason why students do that is they don't know how to learn a language indeed, and the perspective that culture and language can't be separated is lacking for them generally. Hence students have various degrees of pragmatic failure in authentic communicative context with results of unsuccessful cross-cultural communication.

\section{Results and Discussion}

\subsection{The Attitude Towards the Cultural Awareness from Teachers}

In order to further explore the reason for weakness of the students' English cultural awareness, 8 English teachers who come from each primary school participated an interview face to face. All of them are female. Two of them are Han Chinese and the other six are Tibetans. There are two questions: first please talk about what you think of cultural awareness and second have often you been taken culture teaching into English teaching. Here are two samples:

The first teacher is an undergraduate, 10 years for forefront in primary school English education. She says, "Cultural awareness is essential in English teaching, but knowing and action are out-of-step, few of teachers can make it in real English classroom always. They know but don't act, and many of them don't foster cultural perspective intentionally while taking class. Because time is precious, students need to learn and practise words, grammars, reading, writing and so on in limited classroom time. Cultural awareness cultivation is more liking accessory of primary school English teaching, but maybe things are different in Beijing or Shanghai, a good different. Our condition is restricted for many reasons. And for the question 2, yes, I have done it before, but it's not often. I just mention a little it in class and no special culture homework."

The second one, junior college education, 2 years as a English teacher. He says, "Yes, culture is linked with language. It is important to keep culture teaching in primary stage. But our teachers are under huge pressure, so it is necessary to make sure students getting higher scores. Therefore it will not make cultural teaching as a fixed course, and the scale is still in the routine knowledge universally. I can't change the whole thing, but I do intentionally take culture cultivation as much as I can, for example, playing English nursery rhyme or cartoon from Disneyland before class. The world is so unique, and my students need to know that."

From what above teachers and other interviewer said, majority teachers know the importance of culture cultivation. However, they have many limitations in English class. Culture cultivation as dispensable part can be sacrifice for examination. It reflects quality education isn't totally implemented, and the whole education condition is still inclined to exam-oriented education. And many of English teachers don't accept education in real English countries, perhaps this is a huge regret for them.

\subsection{The Attitude Towards the Cultural Awareness from Students}

Culture teaching is in edge zone in actual educational 
environment. After questionnaire, by talking with some students we know that many of them don't have heard the word culture cultivation before, and they don't know what culture is. Even if students know there are many differences between Chinese and English and those differences can make misunderstanding, they don't know how to deal with its in authentic contexts. They actually want to know it better, or maybe we should say they are curious with it. But they give up gradually because teachers don't pay attention to those different things but examinations.

\section{Strategies for Primary School English Teaching}

Compulsory Education Curriculum Standard definitely mentions it is necessary to make student roughly understand the difference and similarity of culture between English countries, also between China and foreign countries at an initial stage, and English countries' culture knowledge need to go hand in hand with students' study and life, as well as stimulating interest in learning English (Ministry of Education 2012). In fact, however, the infiltration of English cultural awareness is ignored, even elliptical. Teachers should guide students to gradually be aware of the importance of English cultural knowledge learning intentionally. It is a progressive process to cultivate cultural awareness for preparing cross-cultural communication and enhancing students' acceptance for Chinese culture besides Tibetan tradition culture.

\subsection{Primary School English Teachers Need to Increase Personal English Culture Quality}

Firstly, as a primary school English teacher, it is necessary to learn the latest teaching ideas and ways, especially theories about culture teaching with over time. Because majority of the teachers in Linzhi District don't have foreign educational background or communicate with English people directly, even many of them without strict professional education result to themselves don't understand the importance between culture and language use indeed. They need to deal with these. At the same time, teachers teach English culture vigorously in class while basing the actual case of school and students, transforming cultural teaching from theory into practice and perfect it for whole English teaching continuously. It isn't only helpful to cultivate elementary cross-cultural communicative awareness and ability efficiently for students but also to increase students' logical thinking and language skills. Secondly, school managements have to share the responsibility of changing ideology for cultural teaching, giving direction for cultural teaching in routine train of teachers. It is essential to know how to teach, the teaching skills, but more important thing is to teach what. It is impossible to change the whole education environment recently, but someone has to start it. Giving up exam-oriented education gradually with concepts change and achieving quality-oriented education truly. The train mainly aims at teachers who are older relatively. Their correspondingly settled mode of thinking is possible to influence culture negative transfer unconsciously for students.

From what have mentioned above, with scientific and advanced teaching ideas, the teacher is capable to be more efficiently to facilitate students' growth, no matter intelligence or mental, meet students' needs of learning, and gradually cultivate students to be better persons as whole.

\subsection{Making Use of Textbook to Compare Cultural Difference for Cultural Infiltration}

Textbook is the basic method of English class. Because students will combine their own cognition and author's opinion to comprehensively analyze, judge and evaluate after understood what text content about correctly, this is the point to foster critical thinking for students. [15] It can yield twice the result with half the effort by utilizing textbook well. Teacher can guide students to explore and think cultural difference between China and English countries by content of text contain English culture, comparing different values while learning for making steppingstone for cultivating critical thinking of students. For example, the story part about Christmas from in Unite 2 What's your favourite season from New PEP, Book 6. This representative overt cultural content in the textbook, the teacher can integrate it with contents from other subjects such as history of Christmas. It is helpful to learn Story time for students understanding English culture better, stimulate motivation and interest for learning English by basing on learning text to expand definite cultural knowledge. [16]

The teacher can make students compare the main similarities and differences between Christmas and Chinese Spring Festival or Tibetan New Year for expanding culture knowledge and fostering national confidence by comprehending Chinese great traditional culture. Wang Qiang mentions the ultimate goal of foreign language teaching is to enable students to use the foreign language in work or life when necessary. [17] In this part, it is advance to create context connected with real life by teacher who can ask students to make greeting cards in English and cos-play postman to deliver it. The Chinese also visit each other with gifts and family reunion in the New Year, which is helpful to do such things for cultivating cultural awareness, and sense of identity for national great culture and gratitude consciousness, also for language skills. Or dog, there are totally different attitudes toward to the word between Chinese and English. Dog, as a family member for English people, and there is proverb 'lucky dog' means lucky man. But in China it will be huge insult if someone is called the dog, which means low or snobbish. And the dog means delicious food in some places, one of points that English think it as brutal killing and incredible. English teachers guide students to think for comparing the different value in team while teaching the word. However, the colour words also can be taught in this way. Every word has different denotative, implicit and associative meanings in diverse cultures. They need to seize appropriate opportunities to base on textbook for culture teaching to take into account to both 
explicit language knowledge and implicit culture knowledge.

While in the part of while-reading, the teacher use resource produced in class to guild students to think deepen gradually. For example, when students are asked what Zoom wants to eat, some of them say Zoom want to eat noodles, then teacher asks again, "Do you like noodles? What is your favor food? Do you think Zoom will eat Chinese traditional food like noodles in London?" The teacher catches every opportunity to ask for training learners' thinking. In the same time, he makes emotional education well permeate into every part of teaching, which yields students to feel and comprehend at learning. Under this way, emotional education and humanity infiltrate are carried though in time without words, and change for story teaching into story learning. For example, the teacher asks students to think how to help 'Zoom' while someone playing Zoom with stomach hurts, which results in that students construct a sense of helping others while they need the help in reality. It is definitely helpful that using textbook well for increasing efficiency of teaching and learning and making students learn better.

\subsection{Various Channels for Cultivating Cultural Awareness by Multimedia}

Considering the characteristics of student's age, actual language ability and cognitive law, for the sake of making them feel learning as the fun and requirement, multimedia is the indispensable method. There are countless resources on the internet. The teacher collects musical and video materials about English culture for making background video or music connected with content in daily life, inserting it into PPT and showing student intentionally what cultures about English life, customs, architectures and so on directly and economically. Also teacher guides students to pour attention to culture compared by digital data. Subsequently it is easy to motivate students' interests towards to English culture. It will be demands for using language to communicate, then bring fluent and affluent language export when student's thinking is active. [18] And it is more than important to designing expansive activities close to student's actual life for increasing their comprehensive language use abilities. [19] For instance, festival topic 'When is Mother's Day?' from Unit 4 When is Easter, New PEP, Book6. The teacher asks students to play a small show in English by team for his or her mother and records it by smart phone for them bringing it home to share with mother. Students are able to evaluate their show each other by teams with given standard. And it is good to enhance feelings for family. Next, the penetration of smart phone is developing rapidly in recent years. Also it can be used for primary school English learning. The teacher gives students tasks about English and Chinese culture, and asks them to do some information search for presenting a report in front of whole class periodically, and it can be finished under help from elders. These ways are not only available for cultivation of cultural awareness, but also for keeping with children's cognitive law and psychological characteristic, on account of actual life.

\section{Conclusion}

Cultivation of cultural awareness can't be achieved overnight and fundamental school stage as a beginning to make steppingstone for cross-cultural communicative competence in the future. Culture teaching, as recessive course of language, influencing students' minds quietly. Understanding culture correctly is the premise for using language reasonably and properly, and it is intensely an important way to compare similarities and differences of culture between Chinese and English counties for understanding Chinese great culture indeed, also for cultivating critical thinking of the student to shape international perspective initially, then for fostering patriotism and national confidence. Perhaps all those things can't be showed its' ways immediately, just like food that have been eaten before. It is impossible to find it, but it does consist in the flesh and blood and becomes part of body. Time will prove things. Primary school English teachers need to perfect their culture qualities and teaching skills both, applying latest teaching philosophy and theory in actual class neatly with using textbook subtly, combining explicit knowledge with implicit influence by available ways for cultural awareness and comprehensive language using ability of students.

\section{Acknowledgements}

Deep gratitude to the following fund items which support this article, including 1. Guangdong Province philosophical social science "The13th Five-Year Plan" 2016 academic construction project "Empirical research on teaching competencies development of primary school teachers in Linzhi District in Tibet"(No. GD16XJY29); 2. China Education Society Foreign Language Teaching Committee "The13th Five-Year Plan "2016 annual issue "English teaching difficulties and solutions in middle schools in Linzhi District in Tibet under the context of trilingual background (No. NAFLE0316028.) 3. 2018 "Strengthen Teachers' Competency" Project: To improve the scientific research ability of primary and secondary school teachers ---“"Research on the UGS model of teacher education"(Project leader: Huangwei).

\section{References}

[1] Sun Ying. A rustic opinion on the integration of language and culture and the infiltration of cultural consciousness in English teaching in primary schools $[\mathrm{J}]$. Forum on Contemporary Education (Subject education research), 2008, (5): 110-112.

[2] Li Jianhua. A Study of Cultural Awareness in English Teaching and Learning [J]. Overseas English, 2012, (12): 126-129.

[3] Dai Weidong, He Zhao Xiong. A New Concise Course in Linguistics for Students of English [M]. Shanghai: Shanghai Foreign Language Education Press, 2013: 124. 
[4] Zhang Yueying. The cultivation of intercultural communication competence in primary school English teaching [J]. Journal of Changchun institute of education, 2013, 24: $190-191$

[5] M. J. Liaghatdar, N. Yamani, F. Mohseni. Cultural Foundations of the Society and Students' Ability for Establishing EFL Teaching in Iranian Primary Schools [J]. Journal of Applied Sciences, 2009: 198.

[6] Zhang Yueying. The cultivation of intercultural communication competence in primary school English teaching $[\mathrm{J}]$. Journal of Changchun institute of education, 2013, 24: $190-191$

[7] Lu Shan, Zhong Wenfang. Explore cultural awareness education in elementary school English teaching [J]. Modern educational science, 2009 (4): 104-106.

[8] Li Yun, Wang Qun, Xing Yaoyao. A Study on the Relationship between Language and Culture [J]. Overseas English, 2010, (6): 291-292.

[9] Li Jianhua. A Study of Cultural Awareness in English Teaching and Learning [J]. Overseas English, 2012, (12): 126-129.

[10] Yang Aijiao. Primary school English teaching should pay attention to the infiltration of cultural awareness [J]. Journal of school of foreign languages, Shandong normal university (basic English education), 2004, (2): 50-52+99.

[11] Liang Shanshan. [A study on cultural teaching knowledge in primary English textbooks -- a case study of primary English textbooks published by people's education press J] Modern primary and secondary education., 2012, (6): 32-34.
[12] Tan Li. The necessity and feasibility of English culture teaching in primary schools [J]. Journal of school of foreign languages, shandong normal university (basic English education), 2003, (1): 24-27.

[13] Guan Jing. Research on cultural consciousness infiltration in English teaching in primary schools under the background of new curriculum standards [D]. Shenyang Normal University, 2014.

[14] Guan Lilan. A case study on the status quo of English cultural awareness training for primary school students in Chongqing [D]. Chongqing Normal University, 2016.

[15] Li Qiuli. The practice of cultivating students' thinking ability in senior grade reading teaching $[\mathrm{J}]$. Foreign language teaching in primary and secondary schools (Primary Schools Essays), 2016, (5): $28-31$.

[16] Shi Minying. Ways to improve the effectiveness of English reading teaching in primary schools $[\mathrm{J}]$. Foreign language teaching in primary and secondary schools (Primary Schools Essays), 2016, (2): 28-32.

[17] Wang Qiang. English teaching methodology [M]. Beijing: higher education press, 2006: 179.

[18] Shen Jia. Case study and countermeasures of inappropriate context creation in primary school English teaching [J]. Foreign language teaching in primary and secondary schools (Primary Schools Essays), 2016, (3): 11-14.

[19] Dong Ling. Strategies for the overall teaching of English units in primary schools $[\mathrm{J}]$. Foreign language teaching in primary and secondary schools (Primary Schools Essays), 2016, (4): $36-40$. 